\title{
Pattern in Modern Clothes Design and Innovation
}

\author{
Linshan Zhang \\ Jiangxi garment college, School of management, Nanchang, jiangxi \\ 28131086@qq.com
}

\begin{abstract}
Keywords: The twelve ornaments; Chinese traditional costumes; Embroidery painting process; Retro elements of modern fashion; Cannes dragon robe
\end{abstract}

\begin{abstract}
Chapter pattern is an important element in Chinese traditional costume culture, in the early Chinese civilization was born at first, the chapter pattern is the typical representative of Chinese culture in their traditional costumes. Chapter but its pattern and only applied to officials, nobles, royal apparel design, it is the symbol of status and rights, is nearly three thousand years Chinese civilization system of clothes and clothing in different ethnic groups in the history of Chinese administration are the inheritance and development, are highly concerned, politics and art. Within the system of totem combination, namely chapter 12 lines (12 chapters, chapter nine, seven chapters, chapter five, chapter three) and on behalf of its assigned to different meaning. Today, China's feudal monarchy era has gone from us, chapter 12 lines go down the history shrines, today's fashion designers are also beginning to bold with chapter pattern dress design and innovation, in the inheritance of ancient traditional Chinese culture at the same time to keep pace with The Times, a positive innovation. In the treasure of the Chinese nation coruscate gives new vitality, weave a beautiful chapter.
\end{abstract}

\section{Introduction}

Chinese culture is a huge boundless energy, the accumulated energy is to accumulate steadily 5000 momentum, gradually into the modern in our daily life, the twelve of this thesis is to explore the modern clothing as the carrier, the design and application of the Chinese culture in the twelve patterns.

\section{The Origin of "Zhang Wen"}

Chapter grain, "grain" is the ear can accurately "case", and "chapter" is considered to be words, but in ancient Chinese, the ancients often use green, red, bright color thread embroidery refers to as "lines", red, white dichromatic line embroidery is called "chapter". Pattern and this chapter in the history books HuiXiu have said is the dress of dragon and phoenix patterns, all kinds of patterns such as skin with acupuncture. Its original meaning is refers to direct form the visual image of the shapes and patterns. Due to the ancient costume design technology, material and feudal culture and the limitation of the class system, that it as the replacement of every dynasty, the development of clothing on the traditional elements of zhang wen is not good to be able to design and innovation. Chapter traditional pattern is what we call "chapter 12 lines". They are "day", representing the sun, often HuiXiu crow in the design of the sun. Based on "between Japan and China have a uri. "Month", representing the moon, the moon's patterns of often with a toad or white rabbit, it is based on "change". "Star" generation refers to the stars in the sky, it is often with a few small circles represent the stars, each a line between the stars is linked together, form a constellation. "Mountain" representing the mountains, its design is usually appears in the mountains form, is not an isolated mountain, is why we see is the endless mountains. "Dragon", is the oldest of the mythical dragon is simplified. And then to, color, species to a variety of dynamic performance of the dragon pattern. "Hua" means "pheasant", actually is to birds. "Zong said implements of ancestral temple". "Seaweed" is representative of the algae, aquatic plants modeling. "Fire" of the human civilization, for the first time refers to the fire, fire Gou shape. "Powder" namely rice, for the grain shape. "Fu" represents the black and white axe, is a tool for human civilization. White biological black blade. 
"Fu is dark green time" traditional "and" zigzag pattern.

\section{Retro Elements in Fashion Apparel}

Chapter twelve grain patterns are originated from the totem worship in ancient times, the twelve kinds of totem represents the ancients to space, natural phenomena, living environment, production resources, production tools, sacrifice and etiquette, as well as a description of the hierarchy of the image. The ancients will this chapter twelve of the most important ZhangWenWen draw in clothing, is the ancient people pursue harmony realm, is the ancient plain pictographic representative of the world. Chapter twelve grain pattern historically, because of long time, some times can't completely textual research. But chapter twelve overall patterns is the development trend of simple to complex, is an extension of its connotation. Now chapter twelve grain pattern retro elements used in modern dress design. In fact, Chinese elements not only stay on paper a design concept. Now, with Chinese elements design products has been more and more, and firmly established in today's fashion trends, has its place. Chinese elements is not only in the domestic many designers research topic and source of inspiration, many foreign designers design and apply of Chinese elements have become adept, and has its unique understanding and insights. Understand the Chinese culture in foreign countries, there are Chinese designers flexible use of classical Chinese architectural art fusion of modern architecture design, there are also industrial designers use of classical Chinese traditional ware shape design and production of industrial electrical appliances. NIKE's designers have launched a new limited edition shoes: James four generations - Chinese red. Designers in the shoe design are unique. This kind of shoe is the theme of the Chinese ancient imperial city gate, shoebox overall modeling is very like the emperor's decree, inside the box and appearance resembling a decree of Chinese seal, this pair of shoes full of rich Chinese classic lasting appeal, the United States sports culture and the Chinese classical culture of fusion. Chinese elements are widely used in the field of various industries, and has emerged a large number of use of Chinese style element design products, these products are widely popular in the fashion circles, so much so that some designers to join in to their own product design "Chinese elements", some strange "Chinese elements" frequently appears, looks weird absurd but thought-provoking. "Weird absurd" reluctantly, of course, also is a kind of unusual design train of thought, breaking the conventional feat can give them to alert the other designers. However, is often a "shanzhai" Chinese element product is not so harmonious. At home, there are some "designer" lack of innovation thinking ability, for the classic design at home and abroad all copied attitude, such as the domestic many designers of all part of the Olympic Games "moire" copying, without its design thinking and ideas. Element is popular in China today, this kind of works without the design inspiration of "Chinese elements", is a mature Chinese elements in the design application of the growing disharmony of pain.

Admittedly, Chinese elements in modern fashion design have become the designers of the new rich. Although is a newly, Chinese elements is not a new thing. China element is the Chinese five thousand years civilization accumulation, broad and profound Chinese culture is the birthplace of Chinese elements. Pay attention to whole Chinese traditional culture, with five thousand years civilization of Chinese elements both in the depth or width has huge excavation potential. For the word "Chinese elements", in this paper, to mention only a drop in the bucket, the purpose of this paper is to expound elements of China and its subtle - chapter of Chinese traditional clothing, a branch system of "twelve articles". It contains Chinese traditional classical elements in the clothing, in addition to the profile, fabric, color, detail design; the most important is about twelve traditional totem pattern the design elements of the design and application.

\section{Application of Fan Bingbing's "Twelve Articles in the Contemporary Fashion Design in Cannes the Design}

Mention the cannes film festival, I believe everyone will not feel strange. Cannes international film festival is one of the most influential international film festival, is also one of the movie event of the cannes film festival in the most prestigious link is "cannes red carpet": in his grand and luxurious 
dress stars cannes red carpet, they are bright at the same time, with his fashionable dress and modeling, has played the role of leading the world fashion fashion leader. And it is the sixty-third cannes film festival, the fan bingbing in "dragon robe" dress as like was born on the red carpet in cannes. The dress is gorgeous, design is heavy and complicated, full of bright yellow imperial style of "dragon robe" with its dazzle beautiful dazzling, moment caught his eye. Not only that, but off the court in silence for a few seconds after unexpectedly suddenly burst into screaming. She wore a post-modern Chinese style dress "dragon robe", is by the Chinese designer Lawrence xu tailored for her. In the evening, fan bingbing also with her "dragon robe" dress won the red carpet world star some third. Chapter 12 lines elements skillfully use bold in modern clothing design show "dragon robe" designer Lawrence xu profound proficiency in use. The article element. In the "dragon robe" design case, to see that Lawrence xu is complete, the design skill he deftly used "chapter 12 lines" in the element, and perfectly to dissolve into the postmodern dress. As the representative work of chapter 12 lines elements, "dragon robe" dress not only get the favor of people, even in a foreign country is widely popular. Can be two dresses in the collection of the museum at the same time, in the modern clothing does not see more, especially in this highly praised and by the museum collection of works carefully, for the designers and the work, this is the highest honor. Investigate its reason, is also in the "dragon robe" dress amazing craftsmanship - Chinese embroidery art and the combination of 12 articles elaborate. According to Lawrence Xu Jieshao, madame tussaud's collection of cannes dragon robe is using a flat embroidery craft, production cost more than a month, more than 30 embroidery workers 24-hour operation by means of shift work. Albert museum collections were put to use an updated version of cannes is a relief to embroider, the dragon is stereo, handmade time longer, by the designer for the assurance of process temperature, and the height of the western tailoring of Oriental elements, upgrade version of cannes dragon robe has been basically achieved the effect of one integrated mass. Whether the use of flat embroidery or embossed embroidery version of cannes dragon robe design elements are the dragon totem of chapter 12 lines within the element is given priority to, so called "dragon robe. Using the dragon totem, designers may has its own considerations, fan bingbing "dragon robe" users may have their own different interpretations. Lawrence xu believes that "the soul of each clothes has its", he is according to the characteristic of each star. That represent the Oriental dragon "myth" of the world, occupies the cannes dragon robe, the center place of honor, is of course an expectation of the designers to work - the ancient Chinese imperial crown clothing mainly dragon totem, also from the inner meaning of chapter 12 lines totem, HuiXiu in yellow satin on the dragon totem, represent power, status, and combines many talents in one's ability, but also both situation. The significance of the more obvious on fan bingbing, performance, as a domestic famous actress, fan bingbing asb in show business, high status can be called power. And versatile fine acting. As tactfully as dragon character, cannes dragon robe and fan bingbing to match your image that is not perfect deduce.

\section{The Impact of Twelve Articles on the World}

Main design idea of modern clothing mainly originated in Europe, in the European and American countries have been extensively used in fashion design to the element of heraldry. With China's twelve articles have the same effect. Europe has long been heraldry, in Europe and the United States has become a mainstream school. Research in Europe and the United States heraldry crest is mainly on behalf of an organization or a group, family badges, badge, like hospitals marks, the police is a branch of heraldry, European and American countries by the heraldry and spawned a huge recognition system, even including the trademark. In general, arms is horizontal relations, social organization is a group of class the premise divided the way of the crowd. Chapter 12 lines mentioned in the article before the last time in China, the large-scale application of the national emblem "golden harvest", as the national emblem is chapter twelve grain design the heraldry a special badge do try, is a kind of match well of Chinese and western creation. While China chapter 12 lines represent the grade and status, is the longitudinal relations of social organization, divided into position, title, the way of the crowd. A vertical and a horizontal, like clothing fabrics of the most basic of channels and collaterals, a line, the product and the thousand silk ten thousand line. It 
is because the article ten million such intertwining yarn, can weave all kinds of, colorful, a variety of clothing.

Arms on behalf of the group, in theory, symbol, with its interests more suitable for the labeling of features, suitable for large-scale industrial production meet the demand of daily clothing, such as gucci, Louis vuitton, hermes amount of luxuries and the luxury apparel production. And on behalf of the rank position of chapter 12 lines, almost represents the highest level of Chinese traditional HuiXiu process, because of its complicated manual weaving and HuiXiu process, expensive materials as well as the more expensive manual, more suited to the route haute couture. "This beautiful can't describe, this love can't interpretation." advanced customization "cannes dragon robe" and as it comes to the shocked the world. Chapter 12 lines HuiXiu is the unique in the world by senior life with its superb technique and through the long time work is created out of work, this is not so much a dress, it is a work of art. The best designer's wit and with sweat art HuiXiu division, in a very strong trend into the mainstream of European and American fashion design, had a profound influence throughout the world.

\section{Conclusions}

Chapter 12 lines in the presence of just three thousand years ago had to show its transformational power. In modern society, chapter 12 lines can represent class level meaning has almost disappear; the left by the twelve patterns represented by the meaning behind it is never out of date. Chapter 12 lines with its exquisite handmade HuiXiu, rich color is tie-in, modeling, and the design of heavy and complicated deeply shocked the European and American clothing designers. Through the understanding of chapter 12 lines HuiXiu works, the world began to accept and large-scale excavation of Chinese traditional elements. In chapter twelve lines, driven by the future more Chinese elements will be on the world fashion stage. Chapter 12 lines make well-dressed replay splendor in the world, let more Chinese design and glory.

\section{Acknowledgements}

The educational reform in Jiangxi Province in 2015 "task driven teaching method in the" CorelDRAW "clothing computer curriculum research and application" stage results, project number: JXJG15-26-5

\section{References}

[1] Gao Chunming Splendid articles - China traditional silk embroideries pattern [M] 2005. Shanghai calligraphy and painting publishing house

[2] Wang Shang Officials in ancient China clothing [J]. 2012 (11) decision making and information

[3] Yan Li dragon use of clothing in China [J]. 2011 (03) border economy and culture.

[4] Xi Yana theory of ancient Chinese "dragon" and "dragon" image, the symbol of development and application [J]. Journal of Hetao University. 2008 (03)

[5] Cai Guangjie dragon pattern of China's traditional costume [J]. Journal of guizhou university (art), 2004 (03)

[6] Yu Shanfeng maple Dragon pattern and the traditional Chinese auspicious culture [J]. Journal of huaibei vocational and technical college. 2009 (04)

[7] Wang Dakai etiquette patterns of the spirit of Chinese traditional clothing decorative aesthetic [J]. Journal of movie review. 2008 (05)

[8] Chang Zheng Talk about the embodiment of the ritual spirit in ancient Chinese clothing patterns [J]. Journal of arts education. 2008 (3)

[9] Jin Hui. The application of Chinese traditional dermatoglyphic pattern in modern clothing 
design [J]. Decoration. 2006 (7)

[10] Yang Yang for grain - spirit of national and traditional patterns appeared [J]. Decoration. 2003 (9) 